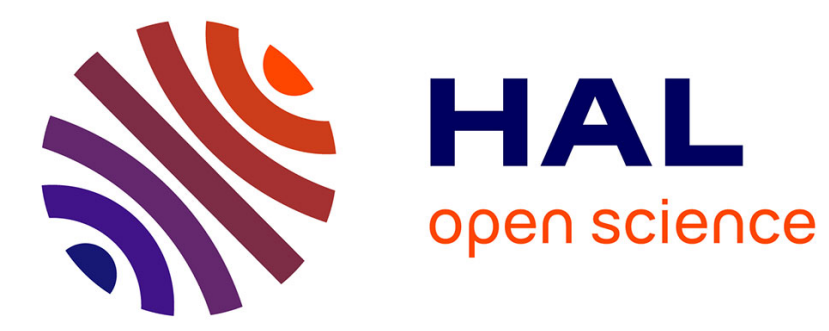

\title{
Cradle to Cradle Products, Modularity and Closed Loop Supply Chains
}

\author{
Kjeld Nielsen, Thomas Ditlev Brunoe
}

\section{To cite this version:}

Kjeld Nielsen, Thomas Ditlev Brunoe. Cradle to Cradle Products, Modularity and Closed Loop Supply Chains. IFIP International Conference on Advances in Production Management Systems (APMS), Sep 2015, Tokyo, Japan. pp.689-696, 10.1007/978-3-319-22756-6_84 . hal-01417635

\section{HAL Id: hal-01417635 \\ https://hal.science/hal-01417635}

Submitted on 15 Dec 2016

HAL is a multi-disciplinary open access archive for the deposit and dissemination of scientific research documents, whether they are published or not. The documents may come from teaching and research institutions in France or abroad, or from public or private research centers.
L'archive ouverte pluridisciplinaire HAL, est destinée au dépôt et à la diffusion de documents scientifiques de niveau recherche, publiés ou non, émanant des établissements d'enseignement et de recherche français ou étrangers, des laboratoires publics ou privés. 


\title{
Cradle to Cradle Products, Modularity and Closed Loop Supply Chains
}

\author{
Kjeld Nielsen \& Thomas Ditlev Brunoe \\ Department of Mechanical and Manufacturing Engineering, Aalborg University, Fibigerstraede \\ 16, 9220 Aalborg East, Denmark \\ kni@m-tech.aau.dk
}

\begin{abstract}
Cradle to Cradle (C2C) is a concept which is gaining acceptance as a way to design products which as a minimum are sustainable. This paper seeks to contribute to the $\mathrm{C} 2 \mathrm{C}$ methodology by providing guidelines for determining product architecture in the product design process, which supports the $\mathrm{C} 2 \mathrm{C}$ concept. The paper describes the linkages between product architecture and reusability in the technosphere (as opposed to the biosphere) which is an enabler for $\mathrm{C} 2 \mathrm{C}$. It is concluded that modular product architecture designing product families based on product platforms rather than designing individual products can enable $\mathrm{C} 2 \mathrm{C}$. Furthermore, reconfigurability also has potential to increase the reusability of parts of products
\end{abstract}

Keywords: Sustainability, eco-design, cradle to cradle, modular architecture

\section{Introduction}

This paper focuses on the specific challenges and opportunities in developing and manufacturing modular products when applying the "Cradle to Cradle" paradigm, and is an extension of the work published by Petersen \& Nielsen [10].

The concept "cradle to cradle" (C2C) was introduced by Michael Braungart and William McDonough [5], [6] as a way to "transform industry from a polluting and resource depleting system into a sustainable system of production". The concept has its origin in the work presented at EXPO 2000 as The Hannover Principles [7]. The main difference between $\mathrm{C} 2 \mathrm{C}$ and traditional initiatives to reduce environmental impact are mainly focused on reducing the harmful impact of a product or process whereas $\mathrm{C} 2 \mathrm{C}$ focuses not on reducing harmful impacts but seeks instead to remove them and replace them with non-harmful elements. One of the elementary ideas behind $\mathrm{C} 2 \mathrm{C}$ is that industrial production should imitate the metabolism of nature where all waste from plants and animals is recycled to create new life by e.g. composting [5]. This is in contrast to the current prevailing industrial system, where products at the end of their useful life are disposed in landfills or incinerated which ultimately pollutes the environment. The materials used for this requires new harvesting of materials often starting in the supply chain as mining or quarrying. The mining and quarry-

adfa, p. 1, 2011.

(C) Springer-Verlag Berlin Heidelberg 2011 
ing required for the new materials for manufacturing products is often resource consuming and polluting processes as well [8]. By introducing the C2C concept, Braungart \& McDonough [5] seek to make a conceptual shift from the cradle to grave paradigm, where the aggregated environmental impact of a product in its single lifecycle is minimized, towards the $\mathrm{C} 2 \mathrm{C}$ paradigm where the negative environmental impact is removed over several product lifecycles and materials are recycled infinitely. Braungart \& McDonough [5] argue that industry should imitate nature by enabling materials used in industry to be recycled closed-loop, ideally without degrading material quality or disposing materials in landfills or incinerators. Materials used in products should either be a) safely disposable in nature by using compostable materials and in this way contribute to renewing nutrients in the nature or farming or b) recyclable in new products by extracting the materials, referred to as technical nutrients, and process them to become usable in a new product without degrading quality [2]. Braungart $\&$ McDonough refer to these two closed loops as the biosphere and the technosphere. In this paper, we shall focus mainly on products in which materials are recycled though the technosphere, i.e. non-organic products. The principles of $\mathrm{C} 2 \mathrm{C}$ design and production are well in conformance with general principles of closed loop supply chains [4], [9], however in this context we will focus primarily on the principles specifically defined for $\mathrm{C} 2 \mathrm{C}$

\section{Cradle to Cradle Products and Production}

Products, which are built from non-organic materials, should according to $\mathrm{C} 2 \mathrm{C}$ be designed to support the material cycle of the technosphere, which is illustrated in figure 1 . The cycle begins with a production process. The output of this process is a product, which for a period is used during its functional life. This part of the life cycle is identical to the traditional cradle to grave thinking, however in the following processes, the life cycle differs. Once the product becomes obsolete or fails, instead of discarding the product in a landfill or incinerating it as would traditionally be the case, the product is disassembled. The disassembly process outputs the components or materials used in the product, which is referred to as technical nutrients. The term "technical nutrient" emphasizes the analogy to the biological cycle, where degraded organic material provides nutrients for new plants or animals. The technical nutrients are then used for a new production process to output new products and thus a closed loop supply chain is achieved, where ideally no technical materials are wasted and no new

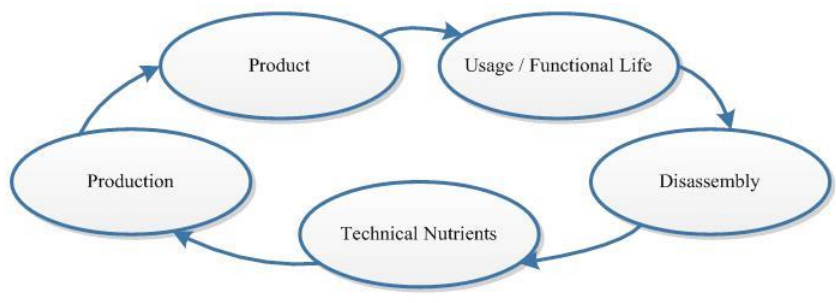

Fig. 1. The cycle of materials in the technosphere [5]. 
materials need to be mined or extracted from natural resources.

It is obvious that the design of a product will determine whether a product can be recycled in the $\mathrm{C} 2 \mathrm{C}$ cycle or not. McDonough et al. [8] links the realization of the $\mathrm{C} 2 \mathrm{C}$ vision to the 12 Principles of Green Engineering, which were first defined by Anastas \& Zimmerman [1]. In the context of this paper, particularly three of these principles are of interests, which are:

- Principle 3: Separation and purification operations should be designed to minimize energy consumption and materials use.[1]

o Principle 9: "Material diversity in multicomponent products should be minimized to promote disassembly and value retention." [1]

- Principle 11: "Products processes and systems should be designed for performance in a commercial "afterlife" [1]

Following normally design procedures, product designs will determine how well these principles can be tracked. In order to follow principle 3, a product should be designed to that after a products useful life, it should be possible to separate it into recyclable materials. This includes that the product should be easy to disassemble into components, but also that the components should be recyclable with as little energy consumption as possible. This must be considered when designing the product by not choosing an architecture that is difficult to take apart as well as avoiding mixing materials in components, which will subsequently be difficult to separate. Principle 9 suggests minimizing material diversity in multiple components products, which is intended to support principle 3. By minimizing the number of different materials used in a product or component, fewer processes will be needed to separate and recycle the material at the end of its life and it will thus be more likely to be recycled. Principle 11 suggests that products, processes and systems should be de-signed for performance in a commercial afterlife; however, the content in this paper shall focus only on products in this context. This principle promotes re-use rather than re-cycling, since reusing a product most often consumes less energy and generally has a much lower environmental impact than recycling it.

Applying these principles naturally presents a number of challenges during product development, since some design considerations may suggest applying other principles than the 12 principles from Anastas \& Zimmerman [1]. As will be shown in the following, choosing the right product architecture will enable the three principles presented above.

\section{Product Modularity and Implications for Cradle to Cradle Products and Production}

It is commonly acknowledged that the usage of modular product architecture is an efficient way of creating the product variety necessary in mass customization [3], [11], [12]. Furthermore, the usage of modular product design has proven to have a number of long-term positive effects on product development as well as manufacturing and logistics [11]. Numerous definitions of modular product architecture exist but 
in this context, the definition of modular product architecture defined by [13] is adopted. This definition states that products with modular architectures have the following properties: 1) One module, being a part of the product implements one or few functional elements and 2) The interactions and thereby interfaces between modules are well defined [13]. This applies to physical products and may to some extent apply to digital products. However, digital products variety can also be implemented without usage of a physical modular architecture, since products can be customized by non-physical means. Ulrich and Eppinger [13] define three different types of modularity: 1) Slot modular architecture, 2) Bus modular architecture, and 3) Sectional modular architecture. In the sectional-modular architecture however all interfaces between modules are identical, implying that modules can be combined randomly and no module is common to all products in a product family. This is in contrast to platform based product families, which are described below.

Modular product architecture broadly defined is often considered the opposite of integral product architecture, in which products are not logically divided in modules with clear interfaces [13]. This architecture is typically chosen for performance reasons, when size is an important optimization issue or if the product is produced in a volume, where the accumulated variable costs exceed the savings from choosing modular architecture.

\subsection{Material Separation and Recycling}

Considering principles 3 and 9, which suggest that separating materials should be as easy and less energy consuming as possible and that material diversity should be minimized, modular product architecture provides a number of possibilities compared to integral product architecture. The industry often tents to use modular product architecture as a way to reduce production complexity and will as a side effect have separated materials before final assembly. Disassembly of such modular products should/would be easier.

Using modular product architecture, components that are manufactured using certain materials can be incorporated into the same modules. This will be beneficial when disassembling the product for recycling, since each module can be regarded as a "product" itself, and following principle 9, this would minimize material diversity. In relation to disassembly and material separation, this is beneficial since each module after being disassembled would not need to be disassembled further to be recycled, assuming it is possible to design modules with only one material. If a module design must have multiple materials, pooling several components of the same material will be beneficial for logistics during disassembly, since each module will be disassembled to fewer material fractions. Using an integral product architecture will then opposite not be useful to fulfill principles 3 and 9. As an example a car wheel, which is modular, but the modules consist of two sub products the rim and the tire. The rim is recyclable, it consists of metal alloy (iron, steel, aluminum, titanium, etc.), but the tire consists of an integration of rubber mixture and metal material (steel) which as the alternative to landfills or incinerators could be re-used, but not re-used. Hence, the use 
of modular architecture makes it easier to follow the principles in design for $\mathrm{C} 2 \mathrm{C}$ and contrary, the use of integrated architecture will likely make this more difficult.

Though ideally all materials used in a product should be recyclable to conform to the $\mathrm{C} 2 \mathrm{C}$ principles, some companies may acknowledge a need for using materials, which cannot be recycled. However, even with some materials, which cannot be recycled, a company may wish to apply $\mathrm{C} 2 \mathrm{C}$ partly by ensuring that the components that do not require the usage of non-recyclable materials can in fact be recycled in compliance with $\mathrm{C} 2 \mathrm{C}$. This can be achieved by defining the product architecture so that recyclable materials are included in certain modules, preferably minimizing material diversity c.f. above, and non-recyclable materials are included in other modules. By doing this, a partial recycling can be promoted as well as a safe disposal of nonrecyclable materials.

\subsection{Afterlife Reuse and Remanufacturing}

In relation to principle 11 , which states that products should be designed for an afterlife performance, modular product design also presents possibilities. However as described above this can primarily be achieved by considering each module as a product itself, so that modules rather than whole products are reused.

One example of this is extending products useful life by allowing end customers upgrade products by replacing a module. This can be achieved if the interfaces in a product are designed so that modules that provide functionality to the user become obsolete can be swapped with a new module providing updated functionality. One example of this is personal computers, where the modular architecture allows the end user to easily replace a hard drive or extension cards to add update functionality or performance. By doing this, the end customer will be able to use the product for a longer time since the product can be upgraded rather than discarded when obsolete.

An important prerequisite for this however is that a part of the product has a more stable functionality, i.e. the architecture should be designed so that "stable" functionality is separated from "unstable" functionality. "Stable" functionality is here defined as functionality that can be considered unchanged for a longer period. "Unstable" functionality is defined as functionality, which compared to the stable functionality needs to be changed more often. To enable product upgrades, and thereby extend the product's useful life, modules should contain either stable or unstable functionality rather than both. This is similar to product development strategies using product platforms in certain companies. When designing product families using a product platform, it is often chosen to include functionality, which is stable in a product platform differentiating the individual products by developing modules that are combined with the platform to form a product. However, the main goal of that effort is to reuse products and upgrade them to extend their life but rather to enable companies to reduce development cost, time and manufacturing costs as well. Although not presently used for supporting $\mathrm{C} 2 \mathrm{C}$ principles, the experiences and methods from product platform development are expected to be possible to apply to $\mathrm{C} 2 \mathrm{C}$ since the product architecture seems similar but with different optimization criteria. 
In the description above, what determines whether functionality is stable or unstable is whether the functionality becomes obsolete. However, other criteria are also relevant in determining the stability of functionality. For some products, it can be expected that the user will change requirements for a certain type of product over time. In order to respect the $\mathrm{C} 2 \mathrm{C}$ principles for such product, it would be necessary to determine which functionality the user would change requirements for most frequently and this functionality would become the unstable functionality.

Another approach, which can be relevant, is to define modules by their expected lifetime before failure. This is mainly relevant if the product contains components, which wear much faster than other leading to an entire product, which could become defect because of a single component or module. In this case, it would be possible to extend the useful life of the product by enabling replacement of the components, which wear fastest. To support this, the architecture could be designed so that fast wearing components are grouped in certain modules, while components that are more durable are grouped in other modules.

However, this approach can only be taken if it is possible to design the product so that the majority of end customers will be able to perform the replacement of modules themselves. If this were not possible, an option would be to allow the manufacturer to take back products once the customer does no longer want to use the product for any reason. Then the manufacturer would be able to process the product by replacing faulty or obsolete modules thereby producing a usable product again much the same way as described above for end customers. A different approach, which is relevant only for the manufacturer, would be to take back products from customers and disassemble the product into modules, which could then be used in a regular production of new products. This is different from the other approaches, since this approach would imply that reclaimed modules are transferred to stock after disassembly rather than whole products being "refurbished". Whatever approaches the manufacturer may choose if reclaiming old products for disassembly the requirements for designing a product architecture are much similar to the case where the customer replaces modules, i.e. grouping functionality by stability or expected time to failure.

\section{$4 \quad$ Implications}

\subsection{Design implications}

As mentioned previously, what is described above can be considered the ideal way of designing product architecture for supporting C2C principles. However, in an industrial environment other considerations will be necessary. Product design decisions are often based on tradeoffs between different criteria. One challenge in designing for $\mathrm{C} 2 \mathrm{C}$ is that optimizing for $\mathrm{C} 2 \mathrm{C}$ may not conform to a company's other design criteria such as cost, performance etc. However at this point, no quantitative research has been conducted to analyze this and generalize the results, so tradeoff decisions would need to be based on case to case analyses.

Furthermore, it seems likely that the different design criteria within $\mathrm{C} 2 \mathrm{C}$ could be contradicting when defining a product architecture. For example grouping similar 
materials in modules to pro-mote recycling of materials could be contradicting the design criteria for grouping functionality in modules to promote module reuse. However, in this specific example, the requirement for reuse would usually be more important than grouping materials since reusing a product, or in this case module, would usually be less energy consuming and have a lower environmental impact than recycling the materials. Furthermore, the considerations regarding materials recycling and thereby grouping similar materials will be more important the shorter lifecycle the module has. I.e. this will be most important in modules with an unstable functionality or shorter expected time to failure.

In general, it is considered necessary to address product design as a design of product families rather than individual products. By thinking a product range as a whole product family, the reuse of modules can become more formalized helping companies to establish methods and procedures for designing products, which are robust to changes in functionality and usage of common modules, which will ultimately facilitate module reuse.

\subsection{Practical implications}

There are a number of different issues, which could prove challenging when designing and manufacturing a product range applying modular architecture to conform to C2C. One issue is logistics. If a company is to reclaim products at the end of their useful lifecycle, logistics must be in place to handle the incoming products. Planning and scheduling of manufacturing using the dis-assembled modules could also prove challenging since it would be difficult to forecast the incoming reclaimed products. However, reverse logistics is already an established research area and solutions are being developed for this.

The length of life cycles for different product types varies vastly. For products, which have a long life cycle, companies may find it difficult to foresee which changes in functionality will be required within the product life cycle. Also for some product types, the product life cycle may even be longer than the company's existence, since an industrial environment is often highly dynamic with companies closing, being acquired or merged. It is obvious that company mergers will pre-sent challenges if reclaiming old product is part of the companies' product strategies.

Although this issue seems most important for products with long life cycles, the matter of deter-mining the stability of functionality can also be in issue for products with shorter life cycles. For some product types companies compete by adding new functionality frequently, which would make it increasingly difficult for a company to determine which functionality will be obsolete in a short time. Hence, this issue can be relevant both to products with short and long life cycles.

\section{Conclusions}

Cradle to cradle is a concept, which is gaining broad attention as a solution to many of the environmental and natural resource challenges, which the world is faced with. 
Although some effort has been put into translating the principles to practical guidelines, it is still difficult to apply the principles in practice. Designing product ranges using modular product architectures however seems to present a number of possibilities to support $\mathrm{C} 2 \mathrm{C}$ principles. The research conducted within modularity as well as companies' own practical experience with this could provide already established methods, which could easily be adapted to $\mathrm{C} 2 \mathrm{C}$ design. However, this paper explores only the potential for applying modular design to $\mathrm{C} 2 \mathrm{C}$, and does not address specific issues practically and does thus not provide evidence that the approach is at all feasible, although it does seem likely.

We consider the issues presented in this paper as an area with a large research potential as well as an area, which could provide industry with guidelines for designing products, which have a lower environmental impact than currently. However, much more research and method development will need to be conducted, for example quantitative studies of product ranges to estimate the actual potential for different product types.

\section{References}

1. Anastas, P. T., \& Zimmerman, J. B.: Design through the 12 Principles of Green Engineering. Environ. Sci. Technol., 37 (2003) 94-101

2. Bolton, S.: Design for a Cradle to Cradle. (2010)

3. Brun $\varnothing$, T. D., Nielsen, K., Taps, S. B. et al.: Sustainability Evaluation of Mass Customization. In: Anonymous Advances in Production Management Systems. Sustainable Production and Service Supply Chains, pp. 175-182. Springer (2013)

4. Hatcher, G., Ijomah, W., Windmill, J.: Design for Remanufacture: A Literature Review and Future Research Needs. J. Clean. Prod., (2011)

5. McDonough, W., \& Braungart, M.: Cradle to cradle: Remaking the way we make things. North Point $\operatorname{Pr}(2002)$

6. McDonough, W., \& Braungart, M.: Design for the Triple Top Line: New Tools for Sustainable Commerce. Corp. Environ. Strategy, 9 (2002) 251-258

7. McDonough, W., \& Braungart, M.: The Hanover Principles: Design for Sustainability. Papercraft, (1992) 8-9

8. McDonough, W., Braungart, M., Anastas, P. T. et al.: Applying the Principles of Green Engineering to Cradle-to-Cradle Design. Environ. Sci. Technol., 37 (2003) 434-441

9. Nielsen, K., \& Brun $\varnothing$, T. D.: Closed Loop Supply Chains for Sustainable Mass Customization. In: Anonymous Advances in Production Management Systems. Sustainable Production and Service Supply Chains, pp. 425-432. Springer (2013)

10. Petersen, T.,D., Nielsen, K., Joergensen, K.,A.: Applying Modular Product Architecture to Cradle to Cradle Product. (2010) 85-91

11. Pine, B. J.: Mass customization: The new frontier in business competition. Harvard Business School Press, Boston, Mass. (1993)

12. Tseng, M. M., \& Jiao, J.: Design for Mass Customization. Annals of the CIRP, 45 (1996) 153-156

13. Ulrich, K. T., \& Steven, D.: Eppinger, Product Design and Development. (2008) 